\title{
Controlling Methods and Causes of Wall Cracks of Civil and Industrial Construction Projects
}

Zhiqi Guan

Kaiyuan Urban and Rural Development Service Center, Tieling 112300, Liaoning Province, China

Abstract: Since the reform and opening up, Chinese economy has developed rapidly. Industrial and civil construction projects have made significant progress. That said, it is of great significance to further strengthen the construction management of industrial and civil construction projects for the longterm development of construction industry in China. In terms of reality, one of the common problems in the current industrial and civil construction is wall cracks, which will have an important impact on the appearance of the building and the overall construction quality. Therefore, it is necessary to analyze the reasons and put forward corresponding measures on it. That is how we can continuously improve the construction quality in civil and industrial construction projects, thereby achieving the enhancement of building safety and stability.

Keywords: Industrial and civil construction projects; Wall cracks; Causes; Control methods

Publication date: November, 2020

Publication online: 30 November, 2020

"Corresponding author: Zhiqi Guan, 573688062@ qq.com

At present, the livelihood is constantly improving, with more and more requirements put forward on housing construction. In the process of building construction, it needs to ensure the living security of the people. It also needs to be more comfortable and beautiful. However, the industrial and civil construction projects is affected by many factors such as design, materials, construction, and management. Among them, there are wall cracks, which have negative impact on the appearance, utility and safety of the building. Therefore, the construction unit should attach more importance to this issue, analyzing the causes of wall cracks, strengthening the corresponding management to ensure that the safety and aesthetics of the building can be guaranteed.

\section{Causes of wall cracks in the construction of industrial and civil construction projects}

Wall cracks are a very significant undesirable phenomena in the construction of industrial and civil construction projects. In order to effectively improve this situation, it is necessary to first analyze the causes of wall cracks: (1) The construction design is unreasonable. The whole construction process is based on the design drawings. It can be concluded that the design work can have an important impact on the overall construction quality. If the designer does not pay attention to the actual conditions of the construction site, the foundation stiffness and other details, it may cause deformation of the formwork and other problems, which may cause wall cracks; (2) Nonuniform settlement. Geological conditions can affect the building. If the construction site exists soft soil, the foundation strength will be insufficient. Nonuniform settlement will easily occur. In addition, if the operating skills of the construction crew are not qualified, it may cause excessive foundation construction spacing. It can also lead to nonuniform settlement; (3) Concrete temperature: The concrete needs to release a lot of heat during the process of setting. When the heat accumulates in the wall, it can cause variations of stress, resulting in wall cracks. Meanwhile, if the temperature of the concrete is too high, it can increase the temperature difference between the inside and the outside. That way, it will further increase the tensile stress of the concrete, 
which easily lead to the appearance of cracks in the wall; (4) Dry concrete shrinkage: If there is rapid evaporation of water in the process of solidification of external wall concrete, it can cause the concrete to shrink and affect the wall stress, which may cause wall cracks; (5) Inappropriate maintenance: Many construction companies do not pay attention to weather factors when maintaining wall. Therefore, the moisture in the cement slurry cannot be dried in the shade in time. Or maybe the evaporation rate is too fast, which may cause the wall to shrink and cracks.

\section{Ways to control wall cracks in the constr- uction of industrial and civil construction projects}

\subsection{Increasing the attention to design}

For the design of industrial and civil construction, it must be in charge by professional designers who are required to have a complete professional knowledge system and relatively rich design experience. This will ensure that the design drawings are reasonable and feasible, thereby reducing the possibility wall cracks. Designers are required to strictly control the details and optimize the design of the wall to ensure that the strength and workability of the wall concrete can meet the relevant requirements. At the same time, the structural reinforcement should be scientifically and reasonably set to strengthen the resistance on cracks and tensile of the wall, which can lower the costs as well. In addition, designers should pay attention to the construction design of the wall pouring, fully considering and strictly controlling the details of the wall temperature, concrete temperature and post-pouring construction. It is to promote the continuous optimization of the construction design scheme, thereby effectively avoiding wall cracks to arise.

\subsection{Strengthening anti-settling treatment}

The phenomenon of nonuniform settlement can do serious harm to the quality and safety of the building. Therefore, the anti-settlement treatment must be continuously strengthened during the construction process. The following two measures are applied frequently in the construction: First, the settlement joints should be reasonably set up. When constructing buildings that is too long with complex plane shapes, the constructors should set the settlement joints reasonably based on relevant data and work experience; second, we should improve the foundation trenching work. If the geological conditions of the construction site are complex, it is necessary to use the drilling method to judge the weak parts and implement reinforcement treatment to promote the foundation to be firmer. This will avoid wall cracks.

\subsection{Improving the accuracy of controlling temperature}

Temperature is one of the main reasons for the appearance of wall cracks, so it is necessary to strengthen the temperature control during the construction process. If there is an excessive temperature difference between the inner and outer parts of the wall, a flexible connection should be used to transfer the temperature stress in the process of pouring concrete. That is how the internal temperature of the wall can always be in a uniform state, thereby eliminating the wall cracks caused by overheated temperature. Moreover, you can also choose to install a thermal insulation layer between the heated layer and the non-heated layer of the building in order to improve the accuracy of the temperature control work to promote uniform temperature dispersion, thereby reducing the impact of temperature stress. That way, we can effectively control the wall cracks, further realizing the improvement of building quality.

\subsection{Strengthening the control of construction materials}

The quality of materials is vital to the quality of construction. If the quality of construction materials is unqualified, it will easily intensify wall cracks. Therefore, construction units are required to procure construction materials through formal channels, carrying out strict and detailed quality inspections thereafter. At the same time, we should optimize the management on construction site and storage of materials. The construction unit should strictly control the quality of cement which is the most important material in wall construction. They should select the appropriate model based on the construction characteristics and corresponding needs. Moreover, they should implement effective moistureproof treatment to ensure that the warehouse is maintaining dry. That is how we can improve the quality of cement, thereby reducing the probability of 
wall cracks.

\subsection{Strengthening construction management}

The entire civil and industrial construction project is centered on the construction stage. Strengthening the quality management work at this stage is conducive to improving the safety and stability of the building. Therefore, the construction unit should establish a scientific, reasonable and complete construction management system, implementing strictly in daily construction. Actually, the professional ability and comprehensive quality of construction personnel can have an important impact on construction quality. Therefore, it is necessary to improve the management of construction personnel during the construction process, carrying out corresponding skill training activities. This will the improve the level of professional skills of personnel. Furthermore, corresponding education needs to be implemented to strengthen the safety and legal awareness of construction personnel. In addition, it is necessary to establish a scientific and rigorous evaluation system based on the actual situation, so as to foster the correct attitude of the construction of the staff. It will minimize the appearance of wall cracks caused by human factors.

\subsection{Attaching more importance on wall mainte- nance}

The corresponding maintenance can also affect the construction quality after it was completed, so the construction unit should pay more attention to the wall maintenance to avoid wall cracks caused by improper measures. It is necessary to fully consider the current weather factors and seasonal changes in the process of wall maintenance. If it is the temperature is too high in summer, we should spring water on the wall to dissipate the heat. This will avoid cracks caused by rapid evaporation of moisture. And if it is in the cold weather in winter, it is necessary to cover the wall with insulation cloth or plastic film to maintain the heat the wall surface. In addition, in order to keep the wall concrete in proper humid condition, the construction personnel should cover the wall with wet sacks and wet grass curtains. They should sprinkle water according to the actual situation to strengthen the functionality and strength of the concrete and reduce the probability of wall cracks.

\section{Conclusion}

The recent years have seen the rapid growth of the construction industry. The competition among construction units has become fiercer. Only by effectively improving the construction level and effectively solving the wall cracks can industrial and civil construction companies stand out from the market. Therefore, it is necessary for industrial and civil construction enterprises to scientifically and rationally apply various wall crack control measures to improve the safety and stability of the building, thereby realizing the sound development of the enterprise.

\section{References}

[1] Song ZB. Cause analysis and control countermeasures of wall cracks in the construction of civil engineering projects $[\mathrm{J}]$. Building materials development guide (Part 2), 2020, 18(1): 93.

[2] Xi WW. Research on the causes and control of wall cracks in the construction of civil engineering projects[J]. Development Orientation of Building Materials (Part 2), 2019, 17(11): 286.

[3] Bai K. Analysis of the causes and control of wall cracks in the construction of civil engineering projects[J]. Building Engineering Technology and Design, 2016, (27): 960-960.

[4] Pang YM. Research on the causes and control of wall cracks in the construction of civil engineering projects $[\mathrm{J}]$. Building Materials and Decoration, 2017(12): 133-134. 